\title{
INOVAÇÃO CIENTÍFICA, TECNOLÓGICA E PEDAGÓGICA: AVANÇOS DA EDUCAÇÃO SUPERIOR
}

\author{
SCIENTIFIC, TECHNOLOGICAL AND PEDAGOGICAL INNOVATION: \\ HIGHER EDUCATION ADVANCEMENTS.
}
INNOVACIÓN CIENTÍFICA, TECNOLÓGICA Y PEDAGÓGICA: AVANCES DE LA EDUCACIÓN SUPERIOR

Andréia Morés

\begin{abstract}
RESUMO
O presente artigo está relacionado aos resultados obtidos em uma pesquisa junto aos cursos de Pedagogia EaD de duas universidades brasileiras: uma federal e outra comunitária. Teve-se o objetivo de investigar as inovações pedagógicas, científicas e tecnológicas dos cursos de Pedagogia EaD de ambas as instituições. A metodologia utilizada foi o Estudo de Caso referendada por Bogdan e Biklen (1994) e Yin (2005). O lastro teórico contempla os embasamentos de Cattani e Holzmann (2006), Furtado e Freitas (2004), Fullan (2000), Messina (2001), Leite, Cunha e Lucarelli et al. (1999), Santos (2006a, 2006b, 2008), Viotto e Macedo (2003), e Leite (2005), Audy (2006), e outros. O estudo revelou que se está a caminho da construção de práticas inovadoras, pois, em ambos os cursos de Pedagogia EaD estão presentes inovações pedagógicas, científicas e tecnológicas que potencializaram uma nova maneira de conhecer, ensinar e aprender na universidade.
\end{abstract}

PALAVRAS-CHAVE: Inovação Pedagógica. Científica e Tecnológica.

\section{ABSTRACT}

This article refers to the results obtained from a research made in Distance Education Pedagogy courses of two Brazilian universities: a federal and a community one. It aimed at investigating the pedagogical, scientific and technological innovations of the Distance Education Pedagogy courses of both institutions. The utilized methodology was the Case Study as backed by Bogdan and Biklen (1994) and Yin (2005). The theoretical background contemplates foundations by Cattani and Holzmann (2006), Furtado and Freitas (2004), Fullan (2000), Messina (2001), Leite, Cunha and Lucarelli et al. (1999), Santos (2006a, 2006b e 2008), Viotto and Macedo (2003), and Leite (2005), Audy (2006), among others. The study revealed that one is on the way to construct innovating practices since both Distance Education Pedagogy courses feature pedagogical, scientific and technological innovations that potentialize a new way of knowing, teaching and learning in the university.

KEYWORDS: Pedagogical. Scientific and Technological Innovation.

\section{RESUMEN}

Este artículo está relacionado con los resultados obtenidos en una investigación de doctorado junto a los cursos de Pedagogía de educación a distancia de las universidades brasileñas: una federal y otra comunitaria. El objetivo fue el de investigar las innovaciones pedagógicas, científicas y tecnológicas de los cursos de Pedagogía a distancia de ambas instituciones. La metodología utilizada fue el Estudio de Caso refrendada por Bogdan y Biklen (1994) y Yin (2005). La base teórica contempla los fundamentos de Cattani y Holzmann (2006),

\footnotetext{
${ }^{1}$ Doutora em Educação - Universidade Federal do Rio Grande do Sul - UFRGS - Porto Alegre, RS. Brasil. Professora do Programa de Pós-Graduação em Educação (PPGEdu), da Universidade de Caxias do Sul (UCS) Caxias do Sul, RS. Brasil. E-mail: anmores18@hotmail.com
} 
Furtado y Freitas (2004), Fullan (2000), Messina (2001), Leite, Cunha y Lucarelli et al. (1999), Santos (2006a, 2006b e 2008), Viotto y Macedo (2003), Leite (2005), Audy (2006), y otros. El estudio reveló que se está en el camino de la construcción de prácticas innovadoras, pues, en ambos cursos de Pedagogía a distancia están presentes innovaciones pedagógicas, científicas y tecnológicas que potencializaron una nueva manera de conocer, enseñar y aprender en la universidad.

PALABRAS CLAVE: Innovación Pedagógica, Científica y Tecnológica.

\section{CAMINHOS INTRODUTÓRIOS}

Imersos no atual contexto educacional, especialmente na educação superior no Brasil, presencia-se o crescimento acelerado da Educação a Distância (EaD), o qual tem gerado desafios e exigências contemporâneas aos tempos e espaços de formação docente. Considera-se que há um avanço nas concepções das políticas da educação superior, principalmente com a promulgação da Lei n. 9.394/96, de Diretrizes e Bases da Educação (LDB), que proporcionou maior flexibilização ao sistema educacional, ampliando e legislando a implementação da EaD no País. Com esse respaldo, a EaD está sendo apontada como uma alternativa para enfrentar o desafio da formação docente no País. Isso no momento em que as propostas de ação governamental são as de ampliar os programas de formação inicial e continuada dos professores, dando autonomia à oferta em instituições públicas e privadas, destaca-se também a Universidade Aberta do Brasil (UAB), com o propósito de melhorar a qualidade da educação.

Assim, o presente estudo contemplou o tema da Inovação, tendo o objetivo de investigar as inovações pedagógicas, científicas e tecnológicas dos cursos de Pedagogia EaD de ambas as instituições, uma pública e uma comunitária ${ }^{2}$. Para a realização da presente investigação, utilizou-se a abordagem qualitativa referendada por Bogdan e Biklen (1994), utilizando a metodologia estudo de caso, embasada em Yin, Robert K. (2005). A construção dos dados contemplou a análise de documentos institucionais e entrevistas realizadas com alunos do Curso de Pedagogia EaD da Universidade de Caxias do Sul (UCS) e da Universidade Federal do Rio Grande do Sul (UFRGS).

Este estudo contempla os referenciais teóricos de Santos (2006a, 2006b e 2008), a fim de compreender o movimento da transição paradigmática que afetou as concepções de conhecimento e se caracterizou pela ruptura da ciência moderna, enquanto única ciência, em prol de uma ciência que atenda à pluralidade das práticas científicas. Nesse contexto de transição, adentra-se nos estudos da inovação com base em Furtado e Freitas (2004), Cattani e Holzmann (2006) e Audy e Morosini (2006) que compreendem a inovação como um fator relacionado à mudança e ao seu processo, no campo da ciência e da tecnologia. Também se adentra na inovação, na perspectiva educacional e pedagógica, com

\footnotetext{
${ }^{2}$ A instituição comunitária, Universidade de Caxias do Sul (UCS), oferece o curso de Licenciatura em Pedagogia EaD particular, sendo pago pelos alunos.
} 
aproximação aos estudos no campo das ciências humanas e sociais dos autores Leite (2005), Leite, Cunha e Lucarelli et al. (1999) que buscam transcender o pensamento dominante sobre o conceito de inovação pedagógica.

\section{A INOVAÇÃo CIENTÍFICA, TECNOLÓGICA E PEDAGÓGICA}

A literatura sobre o tema 'Inovação' mostra diferentes constructos, usos e interpretações sobre a etimologia dessa palavra e o conceito de inovação.

O termo inovação tem sua origem no latim, correspondendo a innovatio, que significa 'renovação'. Em francês, o primeiro registro do uso do termo, com a grafia innovacion, foi em 1297, e significava 'transformação de uma antiga obrigação por substituição de um novo débito ao antigo'. Em inglês, o primeiro registro foi em 1597, mantendo o mesmo significado do termo francês: innovation, no 'sentido de fazer mudanças em algo já estabelecido' e 'introduzir novidade', e, posteriormente, em 1818, transcendeu para 'tornar algo novo' e 'renovar' (MACÊDO, BOAVA, SILVA, MARTINS, 2009).

Já, em língua portuguesa, o termo inovação foi registrado pela primeira vez, no século XIV. Segundo o dicionário Houaiss, inovação significa: “a) ação ou efeito de inovar; b) aquilo que é novo, coisa nova, novidade"; o verbo inovar tem significado de introduzir algo novo em um sistema ou em uma instituição. Contudo, a crescente evolução da ciência e da tecnologia provoca profundas mudanças no âmbito da educação, contribuindo para a inovação, exigindo a produção de novos conhecimentos e saberes, em busca de proposições que atendam as necessidade e demandas dos novos tempos e cenários.

Esse movimento é um desafio para que se repense o viés epistêmico da ciência enquanto princípio arraigado nas concepções do paradigma da modernidade. Os estudos de Santos (2006a) distinguem a epistemologia convencional da ciência moderna e outros sistemas de conhecimento alternativos à ciência, e apresentam duas perspectivas de estudos de ciência e tecnologia: a perspectiva pós-kuhniana dos estudos produzidos no Norte, e os estudos pós-coloniais, muitos deles produzidos no Sul global.

\footnotetext{
A primeira perspectiva, a pós-kuhniana, caracteriza-se pela seguinte abordagem: Postulados históricos e culturais têm conformado a história da ciência moderna ocidental; a ciência progride através de descontinuidades conceptuais; o núcleo cognitivo e técnico da ciência moderna não pode ser isolado da cultura ou da política; as ciências são e devem ser desunificadas; conceber a ciência como um conjunto de representações obscurece a dinâmica da intervenção (SANTOS, 2006a, p.150).
}

Santos (2006a) declara, nessa abordagem, que a ciência produzida é concebida como se houvesse uma única ciência verdadeira produzida no mundo.

A segunda perspectiva, a pós-colonial, concebe a ciência de modo não essencialista, compreendendo que são ambíguas as fronteiras que as separam de outros sistemas de conhecimento; diz que todos os sistemas de conhecimento são sistemas de conhecimento 
local; valoriza a diversidade cognitiva da ciência, concebida em termos de virtualidade tecnológica mais do que em termos representacionais. Também enfatiza que "o sujeito de conhecimento científico, longe de ser um sujeito abstrato, homogêneo, culturalmente indiferente é um conjunto muito diversificado de sujeitos com diferentes histórias, trajetórias e culturas, produzindo conhecimento científico com objetivos igualmente diferenciados" (SANTOS, 2006a, p.151).

Esse conjunto de perspectivas, designadas por Santos (2006a) de epistemologias plurais das práticas científicas, da diversidade e da pluralidade, caracterizam a transição paradigmática. A abertura de uma pluralidade de modos de conhecer as novas formas de relacionamento entre os conhecimentos populares e a ciência, conduzida com resultados profícuos, é importante para construir um mundo verdadeiramente dialógico entre essas duas formas de conhecer. Surge, então, um grande desafio de luta contra a monocultura do saber, não apenas na teoria, mas também na prática constante. Santos (2006a apud NANDY, 1987), afirma que

o futuro não está no retorno a velhas tradições, pois nenhuma tecnologia é neutra: cada tecnologia carrega consigo o peso do modo de ver e estar com a natureza e com os outros. O futuro encontra-se, assim, na encruzilhada dos saberes e das tecnologias (p. 154).

$\mathrm{Na}$ esteira do pensamento de Santos (2006a), compreende-se que a indissociabilidade da ciência e da tecnologia é fator crucial para a compreensão das dinâmicas globais do conhecimento, das desigualdades, tensões e conflitos que atravessam o mundo. Educar para lidar não apenas, e exatamente apenas, com o aparato tecnológico, mas com as informações dele e por meio dele advindas, propiciando, assim, novos conhecimentos e saberes. Para isso, considera-se importante que se entenda o que é tecnologia e sua relação com ciência e inovação. Segundo Cattani, Holzmann (2006, p. 288), o termo tecnologia, contido no Dicionário de Trabalho e Tecnologia, expressa a seguinte concepção:

A tecnologia compreende, portanto, um conjunto de conhecimentos e informações utilizado na produção de bens e serviços provenientes de fontes diversas, como descobertas científicas e invenções, obtidas por meio de distintos métodos, a partir de objetivos definidos e com finalidades práticas.

Por volta do século XVIII, a tecnologia passou a ser usada como significado do melhoramento racional das artes (técnica), especialmente aquelas adotadas pela indústria. $\mathrm{Na}$ Revolução Industrial, a ciência e a tecnologia formaram um binômio com profunda relação com o desenvolvimento do capitalismo, o qual passou a influenciar, em grande medida, o progresso tecnológico e a beneficiar-se dele em formas e níveis de apropriação da natureza.

Assim, compreende-se que a ciência constitui-se de leis e teorias que permitem conhecer a realidade e modificá-la, enquanto a técnica promove a transformação do real, 
constituindo operações, visando a satisfazer determinadas necessidades. No contexto de transição, a inovação associa-se à mudança na esfera da ciência e da tecnologia. Cattani e Holzmann (2006) afirmam que o conceito de inovação vem se desenvolvendo de modo controverso e ideológico, e a inovação, como força produtiva do processo de acumulação do capital, atinge sua "fase de maturação", em meados dos anos 1990, identificado como um período de "mudança de paradigma tecnológico".

Na publicação sistematizada por Viotto, Macedo (2003) sobre Indicadores de ciência, tecnologia e inovação no Brasil, há a seguinte compreensão sobre ciência, tecnologia e inovação:

\begin{abstract}
Elementos-chave para o crescimento, a competitividade e o desenvolvimento de empresas, indústrias, regiões e países. Também, tem importância fundamental na determinação do estilo de desenvolvimento de regiões ou nações e na forma como este afeta no presente e afetará no futuro a qualidade devida da população em geral e de seus diversos segmentos. [...] Influenciam a educação, a informação, a cultura, os costumes e a saúde. Também têm papel relevante nos desígnios da política, da segurança pública, da paz e da guerra. Por tudo isso, a busca da compreensão e o monitoramento dos processos de produção; da difusão e uso de conhecimentos científicos, tecnologias e inovações; como também, dos fatores que os influenciam e de suas consequências é uma tarefa que se impõe (p. 21).
\end{abstract}

Para Viotto e Macedo (2003), a inovação é elemento-chave para o desenvolvimento porque "[...] o conceito de inovação refere-se a um produto ou processo tecnologicamente novo ou substancialmente aprimorado" (p.510). Assim, esse conceito de inovação apresentado por esses autores tem forte envolvimento com a produção de um novo produto inerente ao mercado e à indústria. Esse sistema reconhece que quem tem a capacidade de inovação é a indústria, favorecendo as regiões e países mais desenvolvidos e mais industrializados.

No Brasil, a Lei de Inovação n. 3.476/04 também se refere ao setor produtivo. No art. 2o, inciso IV, apresenta o seguinte conceito: "Inovação: introdução de novidade ou aperfeiçoamento no ambiente produtivo ou social, que resulte em novos produtos, processos ou serviços".

Já, Furtado e Freitas (2004) discorrem sobre a concepção de inovação e destacam que o 'modelo interativo de inovação' considera múltiplas as formas de relação entre a pesquisa e o desenvolvimento:

[...] a relação entre pesquisa e tecnologia se estabelece num duplo sentido. A nova ciência contribui para o avanço tecnológico, mas a nova tecnologia também contribui para o avanço da ciência, como ilustra o caso da informática cujo espetacular avanço potencializou a pesquisa científica no campo genético (FURTADO; FREITAS, 2004, p. 62).

Nessa perspectiva, a atividade de Pesquisa e Desenvolvimento (P\&D) não somente contribui para o crescimento científico e tecnológico, mas representa um importante 
processo de aprendizagem para a organização e para os sujeitos que dela participam. Assim, esse modelo concebe o processo de inovação como multidimensional, e a perspectiva linear é apenas um deles. O processo em seu todo é a "síntese analítica do processo de inovação" (FURTADO \& FREITAS, 2004, p. 62).

Na perspectiva de Audy e Morosini (2006), a inovação é "um conceito associado à ciência e à pesquisa científica e tecnológica" (p.63), sendo a inovação decorrente de uma mudança tecnológica em um produto ou processo que se introduz em determinado contexto. Assim, continuam os autores, "uma inovação deve responder a uma necessidade social, à existência de uma capacidade científica e tecnológica, e à existência de recursos que a viabilizem (humanos, materiais, financeiros)" (p.63). Portanto, para investir nessa concepção de universidade inovadora é preciso, segundo Audy e Morosini (2006), não apenas que haja vontade de alguns dirigentes; é necessária, sim, a criação de políticas institucionais e o desenvolvimento de ambientes de inovação, considerados importantes para as condições de desenvolvimento de um clima voltado à inovação, como ponto de partida para o processo de transformação e renovação do ambiente educacional.

Assim, destaca-se que ao longo dos anos, a inovação tem sido uma referência recorrente também no campo educacional. De acordo com a literatura sobre o tema, a inovação é um termo amplo, capaz de adotar múltiplas formas e sentidos. Segundo Fullan, Michael e Hargreaves, Andy (2000), inovação é antes um processo do que um acontecimento. Assim, não se vê a inovação como um fim em si mesma, mas um meio para transformar os sistemas educacionais.

Segundo Messina (2001, p. 03),

a inovação foi definida como processo multidimensional, capaz de transformar o espaço no qual habita e de transformar-se a si própria. Nesse sentido, diversos autores referem que inovar consiste, antes de mais nada, em uma disposição permanente em direção à inovação.

Parte-se, portanto, da ideia de que o conceito de inovação pode ter diferentes e diversas interpretações. A intenção, neste estudo, é também a de compreender a inovação na perspectiva pedagógica. Para tanto, buscamos aproximar os referenciais sobre inovação no campo das ciências sociais e humanas, destacando-se Santos (2006a), Leite, Cunha e Lucarelli et al. (1999), Leite (2005), que contemplam, no âmbito da educação universitária, experiências e teorias que transgridem o paradigma da ciência moderna.

O grupo de pesquisa Inovação e Avaliação na Universidade (InovAval), e as autoras Leite, Cunha e Lucarelli et al. (1999), em seus estudos, procuram avançar sobre o pensamento dominante mais tradicional sobre o conceito de inovação. O conceito tradicional na literatura pedagógica assim se define: "Inovação é toda tentativa visando consciente e deliberadamente introduzir uma mudança no sistema de ensino com a 
finalidade de melhorá-lo" (OCDE - Organização para o Comércio e Desenvolvimento Econômico apud Leite, Cunha e Lucarelli et al. (1999, p. 42).

Essa concepção perdura até os momentos atuais. Em 1997, o INEP definiu inovação como

toda a experiência educacional que introduz um determinado tipo de mudança na cultura ou prática escolar, através de uma intervenção intencional ou proposital. A mudança precisa obedecer a uma sequência lógica de passos para chegar, com sucesso, ao objetivo estabelecido (MEC CRIE/CRED, 1997, apud Leite et al. (1999), p. 42).

Desse modo a autora enfatiza que deveríamos buscar outras possibilidades, pois as mudanças ou inovações produzidas nas bases de um sistema, no interior de um microespaço educacional, poderiam passar despercebidas, além de que "resistências, tensões e conflitos de um microespaço social, também podem gerar pequenas mudanças e construir inovações, não eram destacadas na literatura consultada" (LEITE, CUNHA e LUCARELLI et al. 1999).

Uma universidade também pode ser inovadora. Para Leite, Cunha e Lucarelli et al. (1999), a inovação na universidade é "um processo descontínuo, de ruptura com os paradigmas tradicionais vigentes no ensino e na pesquisa, ou uma transição paradigmática com reconfiguração de saberes e poderes, que está acontecendo em diferentes espaços acadêmicos e em diferentes universidades" (p.05).

Essa ruptura pode aparecer de diferentes maneiras, e a autora aponta algumas possibilidades:

a) mudança nas relações dentro das salas de aula, onde os sujeitos são protagônicos das suas circunstâncias e aprendizagens;

b) mudança nas relações entre base e decisões centrais na universidade;

c) mudança no caráter epistemológico e espacial do ensino, pesquisa, extensão, numa simbiose produtiva que não destaca relevâncias;

d) mudança na configuração da docência, possibilitando que diferentes atores, tais como: alunos, pessoas da comunidade, professores, pesquisadores e profissionais diversos sejam todos "docentes de saberes diferentes" (LEITE, CUNHA e LUCARELLI et al. 1999, p. 32)

Dessa forma, uma universidade inovadora se caracteriza pelo rompimento com as certezas, os dogmas e as regularidades que marcaram seu passado. Compreendemos, assim, os princípios de inovação pedagógica, seguindo os referenciais de Leite $(2005$, p. 26) que afirmam:

Uma inovação educativa ou pedagógica, por exemplo, se identifica quando e se construída no espaço universitário como um processo descontínuo de rompimento com os paradigmas tradicionais vigentes na educação, no ensino-aprendizagem e na avaliação, ou como uma transição para um modo de ver e fazer ciência e produzir conhecimento onde aconteceria uma reconfiguração de saberes $e$ poderes. 
Seguindo sua reflexão, Leite $(2005$, p. 26) afirma que quando a universidade se propõe a avançar em busca de novos paradigmas "desloca seu olhar para o mundo, à procura de redes e conexões que sejam capazes de mantê-la ligada ao que de melhor existe no campo tecnológico, científico e social". Contudo, inovar, sob a perspectiva pedagógica e educacional, não significa somente a introdução do novo, como lembra Leite em seus vários estudos sobre avaliação e inovação, mas um processo de mudança que não se pode avaliar somente no resultado. O novo é um reflexo, uma representação do processo de mudança; o resultado, um dos momentos desse processo.

\section{PERCURSO INVESTIGATIVO: ANÁLISES DOS CASOS INVESTIGADOS}

É com esse olhar que se procura entender, aqui, as inovações presentes nos cursos de Pedagogia EaD da UCS e UFRGS. Para esta investigação foi utilizada a metodologia qualitativa, embasada nos autores Bogdan e Biklen (1994) e Yin (2005).

A partir da abordagem qualitativa enfatizou-se o Estudo de Caso e, como a expressão sugere, examinou-se o caso em profundidade, em seu contexto natural, reconhecendo-se sua complexidade e recorrendo-se aos métodos apropriados.

\footnotetext{
O estudo de caso é uma investigação empírica que investiga um fenômeno no seu ambiente natural, quando as fronteiras entre o fenômeno e o contexto não são bem definidas [...] em que múltiplas fontes de evidência são usadas (YIN, 2005, p. 13).

É a estratégia de investigação mais adequada quando queremos saber o 'como' e o 'porquê' de acontecimentos atuais (contemporary) sobre os quais o investigador tem pouco ou nenhum controle (YIN, 2005, p. 9).
}

Frente a essa compreensão, o método estudo de caso possibilita a investigação do contexto na vida real em que ele acontece, sendo possível ilustrar certos tópicos, abarcando de modo descritivo e qualitativo o cotidiano; é o estudo da particularidade e da complexidade de um caso singular, levando a entender sua atividade dentro de importantes circunstâncias. Essa metodologia aborda "a observação detalhada de um contexto, ou indivíduo, de uma única fonte de documentos ou de um acontecimento específico" (BOGDAN e BIKLEN, 1994, p. 89).

Assim, a presente investigação contempla um estudo de caso, envolvendo os cursos de graduação em Pedagogia, na modalidade EaD, da UCS e da UFRGS, ambas situadas no estado do Rio Grande do Sul (RS). Considera-se pertinente investigar os dois casos: UCS e UFRGS. O primeiro por apresentar suas experiências enquanto universidade comunitária, que teve sua primeira edição do curso em EaD em 2004, com oferta em 11 polos da região de abrangência da UCS. E o segundo, a UFRGS, pelas experiências enquanto universidade pública federal, com início do curso em 2006, com oferta em cinco polos em sua área de abrangência. Ambas as instituições contam com larga experiência na formação de 
professores e passaram, na atual década, a investir na formação docente em EaD, em especial no Curso de Pedagogia, e, para ambas, esse é o primeiro curso de graduação na modalidade EaD. Destaca-se que em ambas as instituições houve momentos de formação e preparação dos docentes para trabalharem nos referidos cursos, na modalidade EaD.

A partir da investigação realizada, os currículos dos cursos de Pedagogia em EaD dessas duas universidades apresentam a seguinte organização pedagógica: o da UCS está organizado em módulos permeados por eixos temáticos, articulados através do Seminário Integrador, formando uma rede de conhecimentos, reflexões e práticas; e o da UFRGS está organizado em eixos temáticos que agregam e articulam, em cada semestre, os conhecimentos específicos, teóricos e práticos. Os eixos são propostos por Interdisciplinas (grandes áreas que congregam conhecimentos específicos) e Seminário Integrador. Ambos os cursos, contemplam o ambiente virtual de aprendizagem (AVA) como um cenário com diversas interfaces pedagógicas e tecnológicas, propiciando uma aprendizagem ativa e autônoma.

Assim, ao se entrecruzar os estudos teóricos com a investigação realizada observa-se que, perante a análise documental de ambas as Instituições de ensino, Plano de Desenvolvimento Institucional (PDI) e os Projetos Pedagógicos dos Cursos de Pedagogia há, como pressuposto, uma formação acadêmica respaldada em princípios voltados para a autonomia, para a postura reflexiva e crítica e para a participação democrática. Portanto, a teoria possibilita o desenvolvimento de sujeitos ativos no processo de aprendizagem, participantes do processo de planejamento e desenvolvimento do curso.

Nesse contexto, tratar de EaD tem como referência os avanços tecnológicos. Não há dúvida de que as mudanças qualitativas e quantitativas, decorrentes da revolução tecnológica, devem contemplar um horizonte ético e solidário contributivo para a emancipação do homem e para a constituição de uma sociedade mais justa, mais igualitária e mais solidária. Corroborando essa visão, os alunos enfatizam que consideram o curso de Pedagogia EaD inovador, pois, têm-Ihes possibilitado diversos aprendizados que contribuíram qualitativamente para o entrelaçamento teoria/prática, dando visibilidade aos fazeres da prática docente:

Sim, este curso é inovador, como um curso a distância, e por tanto, com características diferenciadas quanto a forma de ministrar o conhecimento, pode ser considerado muito inovador. (Aluna H/TC)

É Inovador sim. Por não relevar atividades em cartilha e propiciar oportunidades de crescimento junto as novas tecnologias. (Aluno G/TC)

Principais inovações são as tecnologias usadas, as interações e discussões do curso, a interação professor-aluno. (Aluna E/SM)

Percebe-se, na concepção dos alunos, que o presente curso apresenta elementos inovadores, buscando superar a lógica de atividades em cartilha, pré-elaboradas, diversificando os recursos, fazendo uso de recursos tecnológicos e pedagógicos. Assim, os 
alunos citam: os guias didáticos, as atividades em grupos, vídeos, fóruns, chats, dentre outros, que contribuíram para a qualificação das práticas docentes, visando possibilitar autonomia aos processos de aprendizagem.

Seguindo esse pensamento, os alunos consideram que as tecnologias utilizadas nos ambientes virtuais de aprendizagem foram muito importantes para o curso em EaD e contribuíram significativamente para sua formação pessoal e profissional.

Eu acho que a internet e o e-mail, que mais que acho que a gente consegue, eu acho que a mais forte é o AVA, eu acho que quando coloco a internet, entra essa a nossa pagina, o AVA onde a gente pode se comunicar, que é ali dentro dele que acontece o curso, eu acho que o fórum ele é bem forte, a fala do especialista, que tem os itens, ai a gente tem guia de trabalho tem páginas, ai que a gente acaba o arquivo, tem todas essas páginas ai presente no AVA, que a gente acaba ocupando diariamente, essas ajudam bastante. (Aluno - B/CX)

Hoje, eu estou tentando convencer algumas colegas a usar o skype como uma forma de comunicação mais barata, econômica, usa o computador pra falar e ver, ao mesmo tempo que estou tentando usar o Google.doc pra tentar falar, ler e escrever ao mesmo tempo a distância,.... eu cito o caso do Orkut que a gente tanto malha, tanto fala mal que tem também muita coisa que não é boa, mas é a nova forma de comunicação da garotada. (Aluno C/CX)

Foram evidenciadas, nos depoimentos dos entrevistados, diversas tecnologias utilizadas durante os cursos, destacando-se, principalmente, o uso do computador, da internet, do ambiente virtual (AVA), dos recursos gratuitos da web: e-mail, skype, Orkut, dentre outros. O uso contínuo das TIC permitiu aos alunos partilharem experiências, socializar saberes em rede, possibilitando que outras pessoas se apropriassem desses conhecimentos, avançando as fronteiras dos espaços físicos de ambas as universidades:

E como tecnologia de informação o computador virou meu livro, uma vez eu lia muito no papel e hoje eu até tomei uma atitude meio drástica, de uns dois anos para cá, eu estou, eu tinha uma grande biblioteca que eu fui ao longo dos anos juntando, os melhores livros, coisas muito importantes que eu tinha e eu acabei mudando toda essa linha de pensamento. Comecei a pensar no volume que eu estava ocupando, o espaço, e eu acabei digitalizando a maioria das minhas coisas, montando uma biblioteca particular ela virou virtual, e aquilo que eu não consegui fazer eu distribuí aos alunos e na biblioteca na escola. Hoje eu já mudei um pouco o conceito, procurar livro na biblioteca pra mim hoje já me dá uma certa preguiça, eu já sou mais de procurar no meio eletrônico, e vejo horizontes para as bibliotecas virtuais. (Aluno - $\mathrm{C} / \mathrm{CX}$ ).

As tecnologias, portanto, implicam mudança de hábitos no ato de aprender, em que o computador passa a fazer parte da vida diária e os alunos passam a ler e-books, artigos, utilizando as bibliotecas digitais, gerando a mudança nos hábitos culturais. Assim, Sancho e Hernández (2006) destacam a importância de educar os alunos para a Sociedade do Conhecimento, para que possam pensar e intervir de forma crítica e autônoma, a fim de solucionar problemas e buscar novas soluções através do uso das TIC. 
Os alunos destacaram a importância da qualidade dos cursos de Pedagogia em EaD em ambas as instituições. Nos relatos fica explícito que o curso exigiu muito dos alunos em relação às leituras, trabalhos, discussões e interações virtuais, sendo bem criterioso com as datas de postagem e com a qualidade da produção, contribuindo para que o aluno se tornasse um sujeito ativo em sua aprendizagem, em prol de um processo de aprender qualitativo.

Sob essa ótica são reafirmados os princípios expressos nos referenciais de qualidade para $\mathrm{EaD}$, de que "um projeto de curso superior a distância precisa de forte compromisso institucional em termos de garantir o processo de formação que contemple a dimensão técnico-científica para o mundo do trabalho e a dimensão política para a formação do cidadão" (MEC - Ministério da Educação, 2007, p. 7). Tornou-se, portanto, evidente, na concepção dos alunos, que os referidos cursos rompem com o preconceito de que é baixa a qualidade dos cursos de EaD, pois, conforme o relato dos entrevistados, ambos os cursos demonstraram profundidade científica e pedagógica, articulados com a inserção tecnológica.

E foi com esse olhar que se adentrou nos estudos da inovação científica e tecnológica, acreditando-se que a inovação, nesse contexto, não significa apenas a produção de um produto novo, mas de um processo de mudança e de ressignificação em determinado contexto. Sob essa concepção volta-se a atenção aos estudos da inovação educacional e pedagógica articulada aos cursos de Pedagogia EaD da UCS e da UFRGS.

Ao se considerar o acima exposto percebe-se a necessidade de analisar as mudanças dos paradigmas das práticas pedagógicas e das formas de transação com o conhecimento. Destarte, cabe à Pedagogia colocar em campo propostas pedagógicas inovadoras que deem conta das reais necessidades vividas; despir-se de determinados tempos e territórios vivenciados em séculos anteriores, abrindo-se à visão global sobre a evolução da ciência e das tecnologias na sociedade do conhecimento. Na visão dos alunos, os cursos devem:

Propiciar uma autonomia para os alunos, de maneira que estes possam construir seus próprios conhecimentos. Justamente refletir individualmente, em nossos lares, sobre os textos e materiais disponibilizados aos alunos. (Aluno G/TC)

Sair da postura de espectador e passar a intervir no próprio processo de aprendizagem.... o estudante constrói seu caminho e seu conhecimento, por ele mesmo, se tornando autodidata, ator e autor de suas práticas e reflexões. (Aluno $\mathrm{H} / \mathrm{TC})$

$\mathrm{Na}$ fala dos alunos, está presente a importância da construção autônoma do conhecimento, havendo, assim, maior significado de apropriação desse conhecimento, em que o aluno avança do estágio de receptor de informações para o de ator desse processo. Nos depoimentos, os alunos enfatizaram a importância de um trabalho que permita a reflexão e a liberdade para construírem o seu caminho, conforme se lê nos fragmentos a seguir: 
Eu acho que o ensino a distância ele exige autonomia, não tem como não se tornar, não buscar isso, porque a gente nota assim, que o curso talvez seja um pouco, ele fica um pouco desacreditado por muitas pessoas, justamente pelo fato de não ter a presença do professor ali no olho, no olho, mas por outro lado, a maioria dos alunos que entraram nessa atividade, nesse curso, assim, como eu pensavam que se tratava de um curso mais fácil, a distancia, eu não preciso ir à aula e tal! Ali um grande engano, ele naturalmente se trata de um curso que te exige mais, ele te dá um grau de dificuldade maior do que o presencial. (Aluno $\mathrm{C} / \mathrm{CX})$

$A$ EaD é o mais puxado, precisamos nos organizar. (Aluno $E / S M$ )

São muitas as exigências feitas pela instituição quanto à seriedade e ao comprometimento com o curso. Inicialmente, encontrou-se presente nas falas dos alunos a possibilidade de ser um curso mais fácil, que demandasse menos tempo de estudo, com menos exigências no acompanhamento dos trabalhos quanto à qualidade $\mathrm{e}$ ao cumprimento da data estipulada para postagem de trabalhos.

Em alguns relatos, os alunos afirmam que a metodologia de trabalho utilizada durante o curso tem “... características diferenciadas quanto à forma de ministrar o conhecimento, que pode ser considerado muito inovador" (Aluno H/TC). Também destacam o uso de metodologias diversificadas e apoiadas em elementos construtivos aos processos de aprendizagem, juntamente com os recursos tecnológicos educativos: "A utilização da tecnologia como metodologia de ensino também é uma inovação muito importante, pois nos abre caminhos a outras experiências e podemos levá-las para nossa prática docente" (Aluno I/TC).

O profissional, ao fazer uso do conhecimento pedagógico e das novas tecnologias para inovar seu trabalho educativo em escolas e outras organizações sociais, assume caráter de garantia, no contexto da prática, para a aprendizagem, conforme se lê no depoimento a seguir.

A metodologia utilizada para nos apresentarem os conteúdos de cada Interdisciplina, nos garante uma aprendizagem concreta, pois sempre temos que aliar teoria e prática.... Ao planejarmos atividades práticas que objetive a teoria estudada e a colocamos em prática, conseguimos ter um melhor aproveitamento e uma melhor aprendizagem do que está sendo exposto. (Aluno I/TC)

Em diversos momentos, a relação teoria/prática destaca-se como um momento importante para a formação e atuação profissional, pois situa o acadêmico na realidade educacional de diversos espaços da sociedade.

Primeiramente, o que foi de mais significativo até agora é a combinação direta da teoria com a prática, pois em todas as Interdisciplinas cursadas, as atividades solicitadas à nós, pediam que colocássemos em práticas para discutirmos os resultados, ou que pensássemos em atividades que contemplasse o que nos era pedido, pensando em alguma turma de Educação Infantil ou Séries Iniciais. (Aluno I/TC) 
Da transposição teórico-prática emergiram questões fundamentais para os espaços acadêmicos de formação. Compreende-se que a teoria oferece instrumentos e embasamento para análise e investigação, permitindo questionar práticas institucionalizadas e primando por práticas que atendam as diversidades e as necessidades presentes no contexto vivido pelos alunos:

\begin{abstract}
As práticas mais importantes foram as que tinham como pressuposto trabalhar levando em conta a realidade dos alunos e suas necessidades. (Aluno J/AL).

Também foram importantes as práticas realizadas a partir das necessidades específicas de determinados alunos, chamados alunos com necessidades educacionais especiais. A partir da cadeira que trata especificamente dos alunos especiais consegui que em minha escola a sala de informática, a biblioteca e a sala de áudio e vídeo fossem reinstaladas no andar térreo da escola. Fruto de discussões que provoquei entre meus colegas após as leituras da interdisciplina Educação de Pessoas com Necessidades Educacionais Especiais. (Aluno J/AL)
\end{abstract}

Constata-se, também, nas falas, uma relação didática e metodológica que primou por desenvolver o conhecimento de formas diferenciadas, gerando, conforme destaca o Aluno D/SM, "uma nova maneira de aprender", imbricada em questionamentos, problematizações que instigam o aluno a pesquisar para aprender. E o Aluno C/CX assim se expressa:

Existiram momentos que a gente teve um pouco de dificuldades assim, porque surgem questões e o sistema nos obriga a pesquisar, mas por outro lado isso também, nos ajuda porque nos dá mais autonomia nessa busca de conhecimento.

Esse movimento metodológico de trabalho proporcionou desafios que, para alguns, soou acompanhado de dificuldades por não terem vivenciando antes esse processo, ou, muitas vezes, por ainda estarem voltados às tradicionais formas de ensino e aprendizagem. Esse trabalho produz maior autonomia ao ato de conhecer, sendo o aluno sujeito ativo do seu processo de aprender, envolvendo especialmente a organização do seu tempo.

Assim, considera-se que a inovação científica, tecnológica e pedagógica é essencial aos processos de ensino e aprendizagem na educação superior. Isto porque a qualidade na educação superior está diretamente imbricada nos avanços científicos e tecnológicos, os quais requerem interligações com as inovações educativas e pedagógicas por serem as que potencializam e mobilizam os processos de ensino e aprendizagem.

\title{
4 CAMINHOS CONCLUSIVOS
}

Ao findar desta escrita compreende-se, juntamente com Leite, Cunha e Lucarelli et al. (1999), Leite (2005) e Santos (2006a e 2006b), que para haver inovação é necessária uma ruptura com a visão paradigmática dominante que perdurou por vários séculos na educação 
superior. Assim, este estudo sinaliza que ambos os cursos de Pedagogia na modalidade EaD da UCS e da UFRGS apresentam pressupostos epistemológicos inovadores.

A inovação científica deve contemplar uma epistemologia fundada no social, no humano e na educação, para além da ciência clássica, positivista e dominante. Conforme Santos (2008, p. 89), essa epistemologia prospera mediante proposições pós-modernas, pois, "a ciência pós-moderna procura reabilitar o senso comum por reconhecer, nesta forma de conhecimento, algumas virtualidades para enriquecer a nossa relação com o mundo". Assim, encontra-se presente em ambos os cursos uma visão libertadora que possibilita, através do diálogo, ampliar o conhecimento científico.

O movimento construtivo abarcou a interligação com a inovação tecnológica, compreendido, neste estudo, de acordo com as concepções de Furtado e Freitas (2004), Sancho (2006), Audy e Morosini (2006), que vão além da compreensão técnica, da elaboração de um novo produto ou da tecnologia como um recurso centrado em um processo de mudança e de ressignificação de determinado contexto. Assim, evidenciou-se que o uso contínuo das tecnologias contribuiu significativamente para estabelecer as interações construídas, nas trocas de experiências e saberes, mediando ativamente os processos de ensino e aprendizagem realizados.

Também se visualizam as inovações pedagógicas contempladas nos processos de ensino e aprendizagem, mobilizadas através de metodologias e práticas pedagógicas que possibilitam, para além da transposição dos processos didáticos de ensino, a construção da aprendizagem autônoma do sujeito. Essa relação parece ter estado presente principalmente nos momentos que tensionaram o fazer docente, de modo a atender ao processo metodológico reflexivo. Esses momentos foram observados em ambos os cursos, pois desafiam a interligação teoria e prática, mediante discussões constantes com os alunos sobre a prática docente, na intenção de superar a linearidade da formação tradicional, estando de acordo com os estudos de Leite, Cunha e Lucarelli (1999), Fullan e Hargreaves (2000).

As inovações destacadas neste estudo potencializam uma maneira de conhecer, ensinar e aprender na educação superior, alargando os horizontes pedagógicos formativos, adentrando na sociedade do conhecimento de forma crítica, autônoma e participativa, em que o uso das tecnologias contempla a aproximação e a socialização de experiências, saberes e conhecimentos construídos em prol de uma sociedade democrática. Portanto, percebe-se que as inovações científicas, tecnológicas e pedagógicas estão presentes no processo de ensino e aprendizagem de ambos os cursos de Pedagogia EaD da UCS e da UFRGS. 


\section{REFERÊNCIAS}

AUDY, Jorge Luis Nicolas. Entre a tradição e a renovação: os desafios da universidade. In: AUDY, Jorge Luis Nicolas e MOROSINI, Marília Costa. Inovação e empreendedorismo na universidade. Porto Alegre: Edipucrs, 2006.

AUDY, Jorge Luis Nicolas e MOROSINI, Marília Costa. Inovação e empreendedorismo na universidade. Porto Alegre: Edipucrs, 2006.

BOGDAN, Robert; BIKLEN, Sari. Investigação qualitativa em educação: uma introdução à teoria e aos métodos. Portugal: Porto, 1994. Tradução da Editora Porto.

BRASIL. Lei no. 9.394, de 20/12/96. Estabelece as Diretrizes e Bases da Educação Nacional. Publicada no DOU de 20 dez., 1996.

BRASIL. Lei no. 3.476/04. Lei das Inovações. Dispõe sobre incentivos à inovação e à pesquisa científica e tecnológica no ambiente produtivo e dá outras providências. Brasília, DF, nov. 2004. Disponível em:

http://win.biominas.org.br/biominas2008/images up/documentos//lei inovacao.pdf

Acesso em: 05 de mar. 2009.

BRASIL. Ministério da Educação (MEC). Referenciais de qualidade em EAD, 2007. Disponível em:

http://portal.mec.gov.br/index.php?option=com content\&view=article\&id=12777\%3Arefer enciais-de-qualidade-para-ead\&catid=193\%3Aseed-educacao-a-distancia\&Itemid=865

Acesso em: 26 abr. 2009.

CATTANI, Antônio David; HOLZMANN, Lorena. Dicionário de trabalho e tecnologia. Porto Alegre: Editora da UFRGS, 2006.

FULLAN, Michael; HARGREAVES, Andy. A escola como organização aprendente: buscando uma educação de qualidade. 2. ed. Porto Alegre: Artmed, 2000.

FURTADO, André; FREITAS, Adriana. Nacionalismo e Aprendizagem no Programa Águas Profundas da Petrobrás. Revista Brasileira de Inovação, Rio de Janeiro, Finep, v. 3, n. 1 p.5586, jan./jun., 2004.

LEITE, Denise; CUNHA, Maria Isabel da; LUCARELLI, Elisa et al. Inovação na Universidade: a pesquisa em parceria, 1999. Disponível em:

http://www.scielo.br/scielo.php?script=sci arttext\&pid=S1414-32831999000100004 Acesso em 10/10/2009.

LEITE, Denise (Org.). Reformas universitárias: avaliação institucional participativa.

Petrópolis: Vozes, 2005.

MACÊDO, Fernanda Maria Felício; BOAVA, Diego Luiz T; SILVA, Renato Duarte; SILVA, Martins, André. Representações sociais de inovação. In: Seminário de Administração, em 27.08.2009, São Paulo. Disponível em: 
http://www.ead.fea.usp.br/semead/12semead/resultado/trabalhosPDF/885.pdf Acesso em: 16 jul. 2010

MESSINA, Graciela. Mudança e inovação. Edu: nota para referência. Cadernos de Pesquisa, n. 114, p. 225-233. nov. 2001. Disponível em:

http://www.scielo.br/pdf/cp/n114/a10n114.pdf Acesso em: 16 jul. 2010.

SANCHO, Juana Maria. De tecnologias da informação e comunicação a recursos educativos. SANCHO, Juana Maria; HERNÁNDEZ, Fernando. Tecnologias para transformar a educação. Porto Alegre: Artmed, 2006.

SANCHO, Juana Maria; HERNÁNDEZ, Fernando. Tecnologias para transformar a educação. Porto Alegre: Artmed, 2006.

SANTOS, Boaventura de Souza. A gramática do tempo: para uma nova cultura política. São Paulo: Cortez, 2006a.

SANTOS, Boaventura de Souza. Conhecimento prudente para uma vida decente: 'um discurso sobre as ciências" revisitado. 2.ed. São Paulo: Cortez, 2006b.

SANTOS, Boaventura de Souza. Um discurso sobre as ciências. 5. ed. São Paulo: Cortez, 2008.

VIOTTO, Eduardo Baumgratz; MACEDO, Mariano de Matos. Indicadores de ciência, tecnologia e inovação no Brasil. Campinas, SP: Unicamp, 2003.

YIN, Robert K. Estudo de caso: planejamento e método. 3. ed. Porto Alegre: Bookma, 2005.

Nota $^{3}$ :

\footnotetext{
${ }^{3}$ Revisão gramatical do texto sob a responsabilidade da Profa. Lou Zanetti. E-mail: kyol@terra.com.br
} 